\title{
Non-thermal gas plasma-induced endoplasmic reticulum stress mediates apoptosis in human colon cancer cells
}

\author{
MADDUMA HEWAGE SUSARA RUWAN KUMARA ${ }^{1}$, MEI JING PIAO ${ }^{1}$, KYOUNG AH KANG $^{1}$, \\ YEA SEONG RYU ${ }^{1}$, JEONG EON PARK ${ }^{1}$, KRISTINA SHILNIKOVA ${ }^{1}, \mathrm{JIN} \mathrm{OH} \mathrm{JO}^{2}$, YOUNG SUN MOK ${ }^{2}$, \\ JENNIFER H. SHIN ${ }^{3}$, YEONSOO PARK ${ }^{4}$, SEONG BONG KIM ${ }^{4}$, SUK JAE YOO ${ }^{4}$ and JIN WON HYUN ${ }^{1}$ \\ ${ }^{1}$ School of Medicine and Institute for Nuclear Science and Technology, \\ ${ }^{2}$ Department of Chemical and Biological Engineering, Jeju National University, Jeju 63243; \\ ${ }^{3}$ Department of Mechanical Engineering and Graduate School of Medical Science and Engineering, KAIST, Daejeon 34141; \\ ${ }^{4}$ National Fusion Research Institute, Plasma Technology Research Center, Gunsan 54004, Republic of Korea
}

Received March 25, 2016; Accepted August 5, 2016

DOI: $10.3892 / o r .2016 .5038$

\begin{abstract}
Colorectal cancer is a common type of tumor among both men and women worldwide. Conventional remedies such as chemotherapies pose the risk of side-effects, and in many cases cancer cells develop chemoresistance to these treatments. Non-thermal gas plasma (NTGP) was recently identified as a potential tool for cancer treatment. In this study, we investigated the potential use of NTGP to control SNUC5 human colon carcinoma cells. We hypothesized that NTGP would generate reactive oxygen species (ROS) in these cells, resulting in induction of endoplasmic reticulum (ER) stress. ROS generation, expression of ER stress-related proteins and mitochondrial calcium levels were analyzed. Our results confirmed that plasma-generated ROS induce apoptosis in SNUC5 cells. Furthermore, we found that plasma exposure resulted in mitochondrial calcium accumulation and expression of unfolded protein response (UPR) proteins such as glucose-related protein 78 (GRP78), protein kinase R (PKR)-like ER kinase (PERK), and inositol-requiring enzyme 1 (IRE1). Elevated expression of spliced X-box binding protein 1 (XBP1) and CCAAT/enhancer-binding protein homologous protein (CHOP) further confirmed that ROS generated by NTGP induces apoptosis through the ER stress signaling pathway.
\end{abstract}

\section{Introduction}

Colorectal cancer is the third most common cancer in males and the second in females, and is thus a severe health threat

Correspondence to: Professor Jin Won Hyun, School of Medicine and Institute for Nuclear Science and Technology, Jeju National University, 102 Jejudaehakro, Jeju 63243, Republic of Korea E-mail: jinwonh@jejunu.ac.kr

Key words: non-thermal gas plasma, endoplasmic reticulum stress, unfolded protein response, CCAAT/enhancer-binding protein homologous protein, apoptosis worldwide (1). Several factors including genetics, gender, ethnic origin, geographical region, and environmental conditions influence the incidence of colorectal cancer (2). Moreover, lifestyle factors such as consumption of processed meat products, high-fat and low-fiber diet, lack of physical activity, and obesity increase the risk of this disease $(3,4)$. Key obstacles to long-term survival of colorectal cancer patients include resistance of the tumors to chemotherapeutic agents and the side-effects of prolonged chemotherapeutic treatments (5).

Non-thermal gas plasma (NTGP), a novel tool successfully used in wound healing and surface sterilization, promotes cell proliferation and increases transfection efficiency $(6,7)$. In addition, this method has recently emerged as a promising approach for treating cancer. The anticancer activity of NTGP has been demonstrated in both in vivo and in vitro models including skin, liver, lung, and colon cancers $(8,9)$. Plasma, considered to be the fourth stage of matter, consists of charged particles (electrons, ions), excited atoms, and reactive oxygen species (ROS) (10). Several lines of evidence suggest that plasma ROS induce apoptosis via oxidative stress (9). Induction of selective cell death in colorectal cancer cells by NTGP treatment represents a promising approach to colorectal cancer therapy that would both avoid the deleterious side-effects of chemotherapy and circumvent chemoresistance.

Cells can undergo apoptosis via three different pathways, respectively mediated by death receptors, mitochondria, or the endoplasmic reticulum (ER) (11-13). The ER is the primary site for synthesis and folding of secreted and membrane-bound proteins, as well as some organelle-targeted proteins. This organelle is highly sensitive to stresses that perturb cellular energy level, redox state, or $\mathrm{Ca}^{2+}$ concentration (14). Protein chaperones such as glucose-related protein 78 (GRP78)/BiP and GRP94 maintain the correct folding of newly synthesized proteins in the ER (15). High ROS levels disturb ER function, leading to accumulation of unfolded proteins and a state referred to as ER stress. In response to ER stress, the cell activates signaling pathways including the unfolded protein response (UPR) and ER-associated protein degradation (ERAD) $(16,17)$. The UPR, the primary defense 
mechanism of the ER, restores cellular function by halting protein synthesis and bolstering protein folding capacity, thereby improving the cell's likelihood of survival (17). However, when ER stress is so severe that these tactics cannot restore cellular homeostasis, the UPR triggers apoptosis (16).

Because plasma generates ROS, resulting in oxidative stress, we predicted that NTGP would induce ER stress in SNUC5 human colon cancer cells and thereby cause apoptosis. The effects of the plasma exposure depend on the plasma source (e.g., plasma jet or needle, surface or volume of plasma), exposure time, and process gas (e.g., air, argon or helium) (18). For this study, we used a non-thermal dielecteic barrier discharge (DBD) plasma source with a gas consisting of $70 \%$ oxygen and $30 \%$ argon at atmospheric pressure. Previously, we showed that a DBD plasma system can generate ROS and induce apoptosis in human keratinocytes (19), and we used the same experimental settings for this study.

\section{Materials and methods}

Reagents.3-(4,5-Dimethylthiazol-2-yl)-2,5-diphenyltetrazolium bromide (MTT), 2',7'-dichlorodihydrofluorescein diacetate (DCFH-DA), $N$-acetylcysteine (NAC), and anti-actin primary antibody were purchased from Sigma-Aldrich (St. Louis, MO, USA). ER-Tracker ${ }^{\mathrm{TM}}$ Blue-White DPX and Rhod-2 AM dyes were purchased from Molecular Probes, Inc. (Eugene, OR, USA). Primary antibodies against GRP78, phosphorylated eukaryotic initiation factor $2 \alpha$ (p-eIF2 $\alpha$ ), phosphorylated PERK (p-PERK), and X-box binding protein 1 (XBP1) were purchased from Santa Cruz Biotechnology, Inc. (Dallas, TX, USA), and anti-CHOP antibody was purchased from Cell Signaling Technology, Inc. (Beverly, MA, USA). Primary antibody against phosphorylated IRE1 (p-IRE1) was purchased from Thermo Fisher Scientific, Inc. (Rockford, IL, USA).

Cell culture. The SNUC5 colon cancer cell line was obtained from the Korean Cell Line Bank (Seoul, Republic of Korea). Cells were cultured at $37^{\circ} \mathrm{C}$ in an incubator containing humidified air (95\%) and carbon dioxide (5\%). The culture medium was RPMI-1640 (Invitrogen, Grand Island, NY, USA) containing 10\% heat-inactivated FBS (Sigma-Aldrich), streptomycin $(100 \mu \mathrm{g} / \mathrm{ml})$, and penicillin $(100 \mathrm{U} / \mathrm{ml})$.

Plasma treatment. Non-thermal DBD was used as the plasma source, as previously described (19). For DBD plasma treatment, cells were trypsinized and counted to adjust the density to $2 \times 10^{5}$ cells $/ \mathrm{ml}$, and $11 \mathrm{ml}$ of cell suspension was placed in a 60-mm cell culture dish. After exposure to DBD plasma, cell suspensions were transferred to new cell culture dishes or wells for subsequent experiments. Control samples were subjected to all steps except plasma exposure.

Detection of intracellular ROS. Plasma-treated cells were seeded at a density of $1 \times 10^{5}$ cells/plate and incubated for $24 \mathrm{~h}$ at $37^{\circ} \mathrm{C}$. Cells were then harvested, washed, and re-suspended in PBS containing $25 \mu \mathrm{M}$ DCFH-DA. After $15 \mathrm{~min}$ at $37^{\circ} \mathrm{C}$, the cells were washed, re-suspended in PBS, and analyzed by flow cytometry (Becton Dickinson, Mountain View, CA, USA). For image analysis, cells were loaded with DCFH-DA and incubated for $30 \mathrm{~min}$ at $37^{\circ} \mathrm{C}$. The stained cells were washed and mounted on microscope slides in mounting medium (Dako, Carpinteria, CA, USA). Microscopic images were obtained on a confocal laser-scanning microscope and analyzed using LSM 5 PASCAL software (Carl Zeiss Jena $\mathrm{GmbH}$, Jena, Germany).

Cell viability. Cell viability was assayed by MTT test. Cells were suspended in $11 \mathrm{ml}$ of media at a density of $2 \times 10^{5}$ cells $/ \mathrm{ml}$, and the suspensions were placed in $60-\mathrm{mm}$ cell culture dishes. With the lids removed from the dishes, the cells were exposed to plasma for $2 \mathrm{~min}$. Plasma-treated cells were transferred to 24 -well plates at a density of $1 \times 10^{5}$ cells/well. Twenty-four hours later, $50 \mu \mathrm{l}$ of MTT stock solution $(2 \mathrm{mg} / \mathrm{ml})$ were added to each well to yield a total reaction volume of $200 \mu \mathrm{l}$. After incubation for $4 \mathrm{~h}$, the plate was centrifuged at $800 \mathrm{x} \mathrm{g}$ for $5 \mathrm{~min}$, and the supernatants were aspirated. Formazan crystals in each well were dissolved in $150 \mu \mathrm{l}$ of dimethylsulfoxide (DMSO), and $\mathrm{A}_{540}$ was measured using a scanning multi-well spectrophotometer (20).

Nuclear staining with Hoechst 33342. Cells were transferred into 24-well plates following plasma exposure and incubated at $37^{\circ} \mathrm{C}$ for $24 \mathrm{~h}$. The DNA-specific fluorescent dye Hoechst 33342 was added to each well, and the cells were incubated for $10 \mathrm{~min}$ at $37^{\circ} \mathrm{C}$. The stained cells were visualized under a fluorescence microscope equipped with a CoolSNAP-Pro color digital camera. The degree of nuclear condensation was evaluated by counting apoptotic cells in randomly selected equally sized areas in each well.

ER staining. Plasma-exposed cells were seeded in chamber slides (Nalge Nunc International Corp., Rochester, NY, USA) at a density of $1 \times 10^{5}$ cells $/ \mathrm{ml}$ and incubated for $24 \mathrm{~h}$ at $37^{\circ} \mathrm{C}$. ER-Tracker ${ }^{\mathrm{TM}}$ Blue-White DPX dye was added to the cells, and the samples were incubated for an additional $30 \mathrm{~min}$. The cells were washed twice with PBS before the addition of mounting medium. Microscopic images were collected using LSM 5 PASCAL software.

Western blotting. Harvested cells were lysed by incubation on ice for $30 \mathrm{~min}$ in $150 \mu \mathrm{l}$ of lysis buffer (iNtRON Biotechnology, Seoul, Republic of Korea). The resultant cell lysates were centrifuged at 13,000 rpm for $5 \mathrm{~min}$. Supernatants were collected, and protein concentrations were determined. Aliquots were boiled for $5 \mathrm{~min}$ and electrophoresed on $12 \%$ SDS-polyacrylamide gels. Protein blots of the gels were transferred onto nitrocellulose membranes. The membranes were incubated with the appropriate primary antibodies $(1: 1,000)$ followed by horseradish peroxidase-conjugated anti-IgG secondary antibodies $(1: 5,000)$ (Pierce, Rockford, IL, USA). Protein bands were detected using an enhanced chemiluminescence western blotting detection kit (Amersham, Little Chalfont, UK).

Measurement of mitochondrial $\mathrm{Ca}^{2+}$ levels. Mitochondrial $\mathrm{Ca}^{2+}$ levels were measured using Rhod-2 AM (21). Plasma-treated cells were seeded at a density of $1 \times 10^{5}$ cells/plate and incubated for $24 \mathrm{~h}$ at $37^{\circ} \mathrm{C}$. Cells were harvested, washed, and re-suspended in PBS containing Rhod-2 AM. After $15 \mathrm{~min}$ at $37^{\circ} \mathrm{C}$, the cells were washed, re-suspended in PBS, 
A
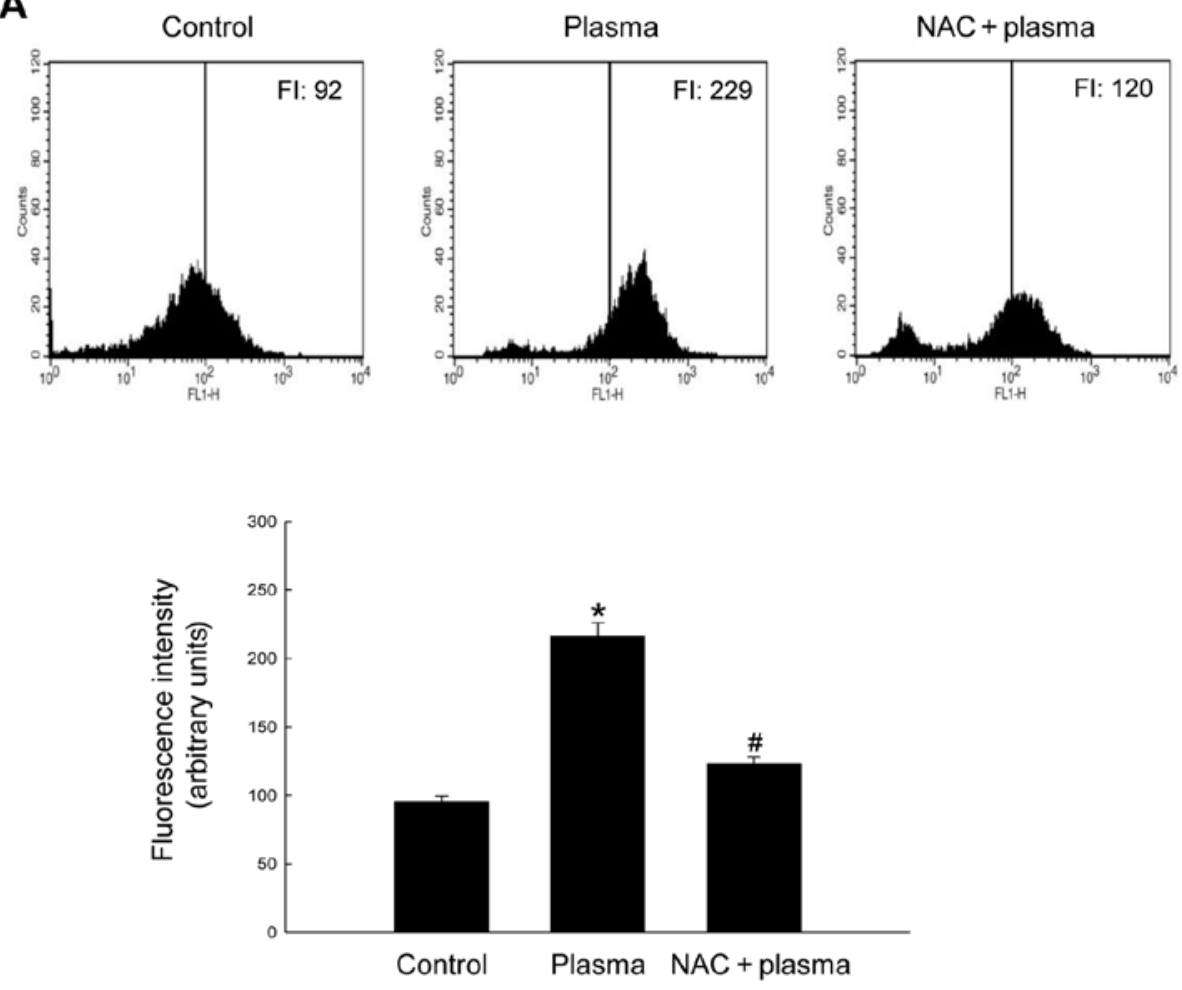

B
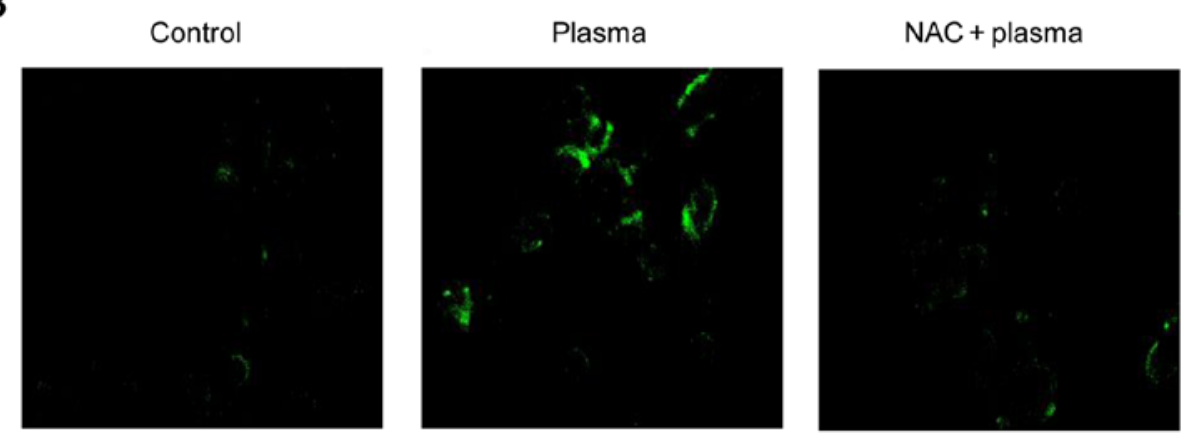

Figure 1. Effect of NTGP on ROS generation. NAC was used as a ROS scavenger. SNUC5 cells were placed in 60 -mm cell culture dishes in $11 \mathrm{ml}$ of media at a density of $2 \times 10^{5}$ cells $/ \mathrm{ml}$. With the lids removed from the dishes, the cells were exposed to plasma for $2 \mathrm{~min}$. Plasma-treated cells were stained with DCFH-DA

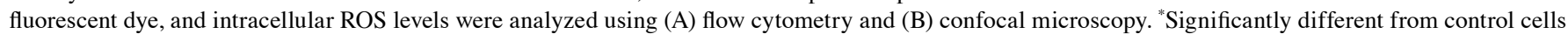
$(\mathrm{p}<0.05)$; "significantly different from plasma-exposed cells ( $<<0.05)$. NTGP, non-thermal gas plasma; ROS, reactive oxygen species; NAC, $N$-acetylcysteine.

and analyzed by flow cytometry. For image analysis, cells were loaded with Rhod-2 AM and incubated for $30 \mathrm{~min}$ at $37^{\circ} \mathrm{C}$. The stained cells were washed and mounted on microscope slides in mounting medium. Microscopic images were obtained under a confocal laser-scanning microscope and analyzed using LSM 5 PASCAL software.

Statistical analysis. All measurements were made in triplicates, and all values are expressed as means \pm standard error of the mean (SEM). The results were subjected to analysis of variance (ANOVA) using the Tukey's test to analyze differences. $\mathrm{P}<0.05$ was considered statistically significant.

\section{Results}

NTGP induces ROS level in SNUC5 cells. Plasma generates ROS and induces oxidative stress in cells (9). Therefore, we assessed intracellular ROS generation in plasma-treated cells using DCFH-DA, a ROS-sensitive fluorogenic dye. Flow cytometry revealed that $2 \mathrm{~min}$ of plasma exposure increased DCFH-DA fluorescence to 229 (FI: 229) vs. 92 in control cells not exposed to plasma (Fig. 1A). Samples pre-treated with NAC, a well-known free radical scavenger, yielded an FI value of 120 . The flow cytometry results were consistent with those obtained by confocal microscopy analysis of DCFH-DA-stained cells (Fig. 1B). These results indicate that NTGP generates ROS in SNUC5 human colon carcinoma cells.

NTGP induces apoptosis in SNUC5 cells. MTT assay results revealed that plasma treatment markedly decreased cell viability (55\% relative to untreated controls). This reduction in viability was rescued by treatment of NAC prior to plasma exposure (Fig. 2A). Next, we investigated whether cells would undergo apoptosis following plasma exposure using the nuclear staining dye Hoechst 33342 . As shown in Fig. 2B, 


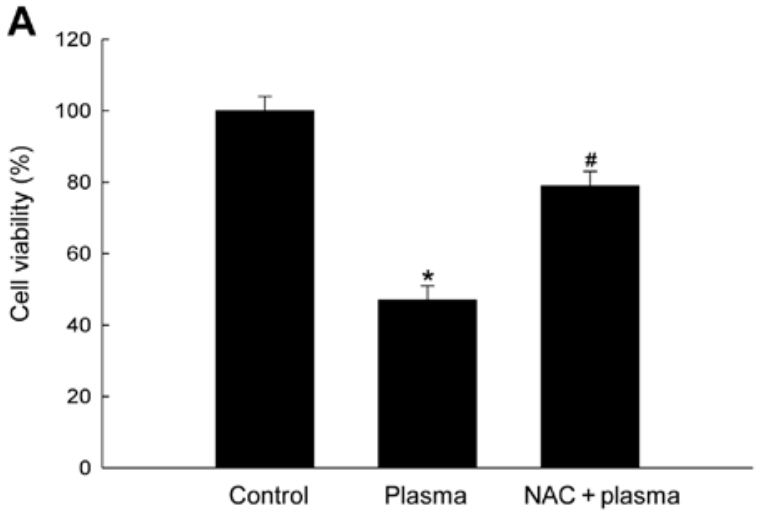

B
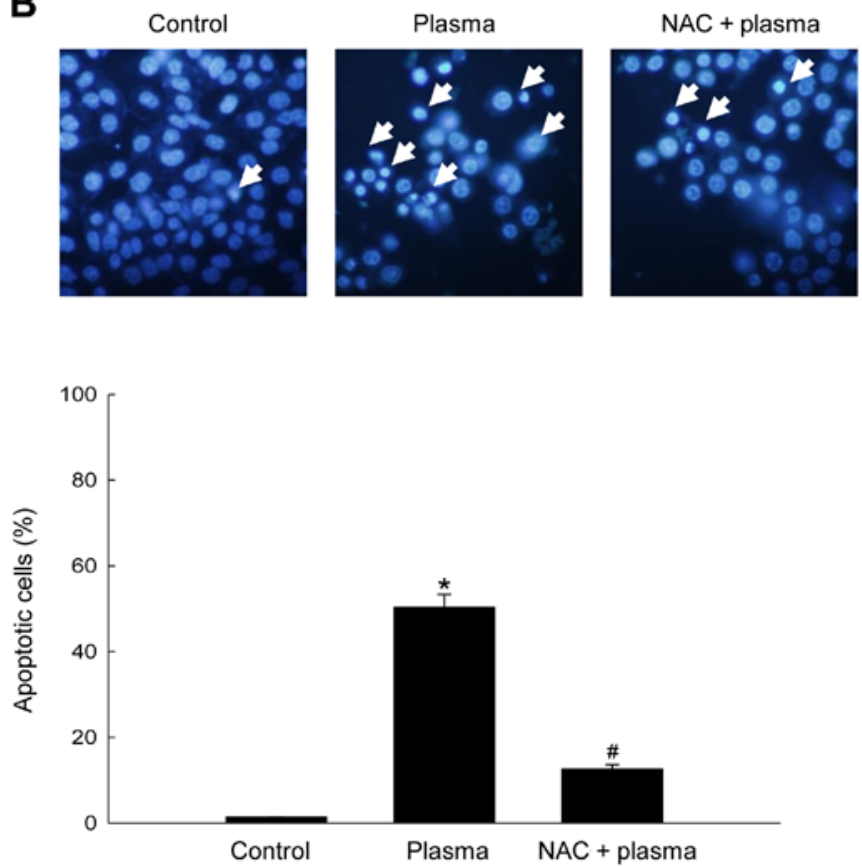

Figure 2. Effect of NTGP on apoptosis. (A) SNUC5 cells were plated in 60-mm cell culture dishes in $11 \mathrm{ml}$ of media at a density of $2 \times 10^{5}$ cells $/ \mathrm{ml}$. With the lids removed from the dishes, cells were exposed to plasma for $2 \mathrm{~min}$. Cells exposed to plasma were transferred to 24 -well plates at a density of $1 \times 10^{5}$ cells/well. Cell viability of control, plasma-treated, and NAC-pre-treated/plasma-treated cells were measured by MTT assay. (B) Cells were transferred into a 24-well plate followed by plasma exposure and incubated at $37^{\circ} \mathrm{C}$ for $24 \mathrm{~h}$. The DNA-specific fluorescent dye Hoechst 33342 was added to each well, and cells were incubated for $10 \mathrm{~min}$ at $37^{\circ} \mathrm{C}$. Stained cells were visualized by fluorescence microscopy, and apoptotic bodies were counted in randomly selected areas. *Significantly different from control cells $(\mathrm{p}<0.05)$; ${ }^{\#}$ significantly different from plasma-exposed cells $(\mathrm{p}<0.05)$. NTGP, non-thermal gas plasma; NAC, $N$-acetylcysteine.

$>50 \%$ of plasma-exposed cells underwent apoptosis, as indicated by the formation of apoptotic bodies. Again, NAC pre-treatment diminished the formation of apoptotic bodies. These results suggest that NTGP induces apoptosis via ROS generation in SNUC5 cells.

Plasma-induced apoptosis in SNUC5 cells is mediated by ER stress. Overwhelming ROS levels cause ER stress (16). Therefore, we next investigated whether plasma exposure can induce ER stress. To this end, plasma-exposed cells were stained with ER-Tracker ${ }^{\mathrm{TM}}$ Blue-White DPX dye, and were observed by confocal microscopy. Under these conditions, plasma-exposed cells stained bright blue, indicative of ER stress (Fig. 3A); as with the loss of viability and apoptosis described above, pre-treatment with NAC prior to plasma exposure decreased the brightness of staining, demonstrating that ER stress in plasma-treated cells arises due to high levels of ROS.

To confirm the induction of ER stress upon plasma exposure, we analyzed ER stress-related proteins. The UPR is a suite of signaling pathways that cells activate to restore cellular homeostasis once ER stress has occurred. Cells that are unable to achieve homeostasis undergo apoptosis (22). The ER-resident transmembrane receptors PERK (pancreatic eIF2- $\alpha$ kinase or protein kinase R (PKR)-like ER kinase), inositol-requiring enzyme 1 (IRE1), and ATF6 are maintained in their inactive forms through association with GRP78, which dissociates upon ER stress. Upon GRP78 dissociation, the UPR receptors are activated by phosphorylation (15). Western blotting revealed that the expression of GRP78, which is itself a transcriptional target of the UPR, increased dramatically following plasma treatment (Fig. 3B). Furthermore, levels of p-IRE1 and p-PERK were significantly elevated following plasma exposure, suggesting that plasma exposure induces the UPR in SNUC5 cells. In accordance with the data presented above, NAC pre-treatment attenuated upregulation of GRP78 and phosphorylation of both IRE1 and PERK. Activated PERK phosphorylates eIF2 $\alpha$, leading to inhibition of general protein translation, a hallmark of the UPR (23). Plasma exposure increased the level of p-eIF $2 \alpha$, confirming the activation of the UPR; as with the other indicators of UPR activity, the p-eIF2 $\alpha$ level decreased in NAC-pre-treated cells (Fig. 3B).

Next, we investigated whether the UPR restores ER function or initiates apoptosis in SNUC5 cells. After non-conventional splicing of the XBP1 mRNA by IRE1, XBP1 protein translocates to the nucleus, where it induces transcription of genes involved in protein degradation and inhibition of the PERK-mediated translational block (24). At this stage, if the UPR has restored homeostasis, the cell will survive; otherwise, it will be driven to apoptosis. Expression of CCAAT/enhancer-binding protein homologous protein (CHOP), also known as growth arrest and DNA damage-inducible gene 153 (GADD153), is activated by the UPR; CHOP downregulates the anti-apoptotic mitochondrial protein Bcl-2 (25), fostering a pro-apoptotic environment and stimulating the mitochondria to release cytochrome $c$ and activate caspase-3. Our data revealed that plasma exposure increased the expression of both XBP1 and CHOP, indicating that ER stress exerted by NTGP causes apoptosis in SNUC5 cells. All of the aforementioned effects were suppressed by the pre-treatment with NAC prior to plasma exposure.

Mitochondrial $\mathrm{Ca}^{2+}$ overloading is involved in plasma-mediated ER stress. ER stress is characterized by various molecular markers; for example, depletion of $\mathrm{Ca}^{2+}$ from the ER and accumulation of $\mathrm{Ca}^{2+}$ in mitochondria are hallmarks of severe ER stress (26). Therefore, we detected mitochondrial $\mathrm{Ca}^{2+}$ overload in plasma-exposed cells using Rhod-2 AM fluorescent dye. Flow cytometry revealed a significant increase in the mitochondrial $\mathrm{Ca}^{2+}$ level in plasma-treated cells (FI: 148) relative to that in controls (FI: 97) (Fig. 4A), which was attenuated (FI: 128) by pre-treatment with NAC 

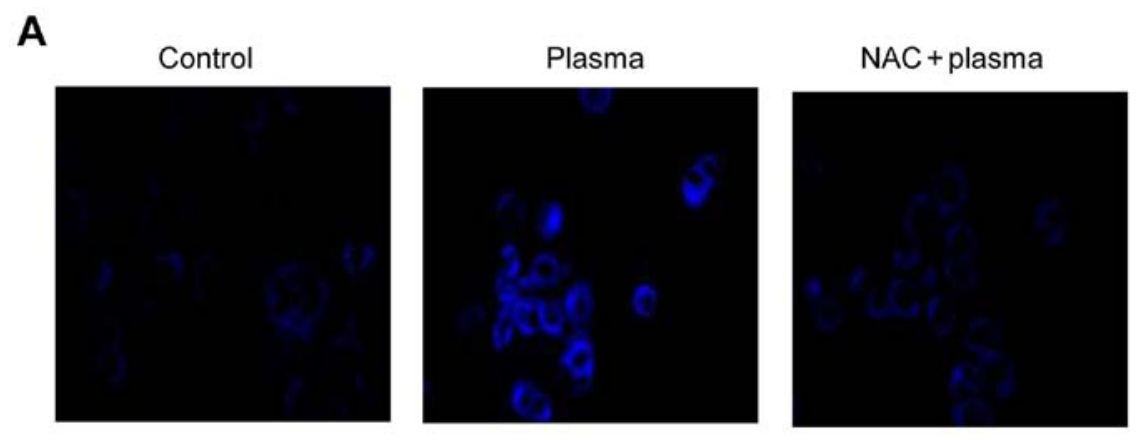

B

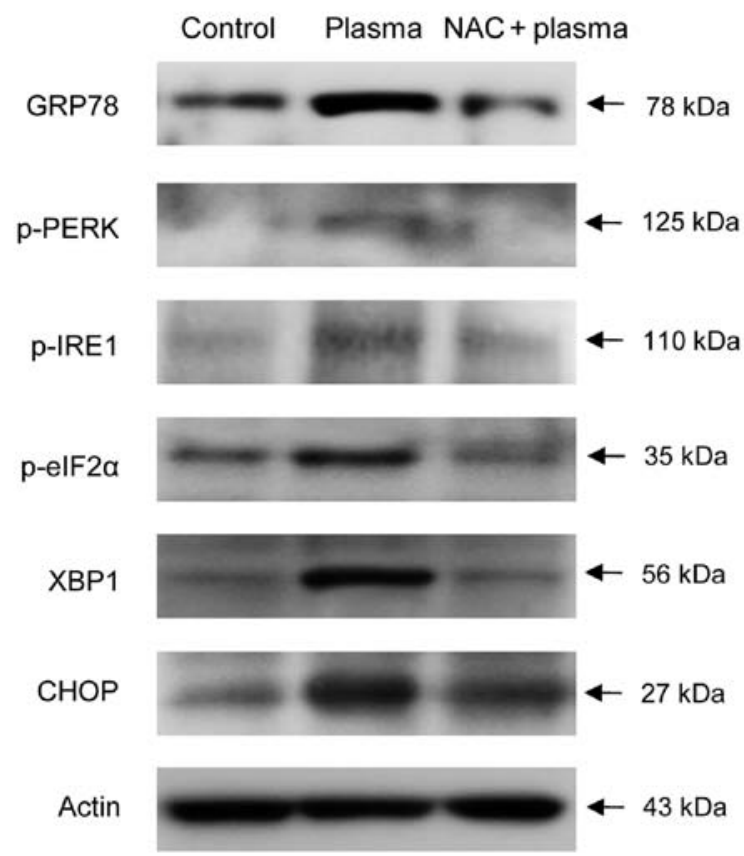

Figure 3. NTGP induces ER stress. (A) Cells were exposed to plasma and incubated for $24 \mathrm{~h}$ at $37^{\circ} \mathrm{C}$, and then ER-Tracker ${ }^{\mathrm{TM}}$ Blue-White DPX fluorescence staining dye was added and ER stress was analyzed by confocal microscopy. (B) SNUC5 cells were exposed to plasma and incubated for $24 \mathrm{~h}$ at $37^{\circ} \mathrm{C}$. Cells were harvested, and the proteins were extracted. Expression levels of GRP78, p-PERK, p-IRE1, p-eIF2 $\alpha$, XBP1, and CHOP proteins were evaluated using western blotting. Actin, a housekeeping protein, was used to confirm equal protein loading. NTGP, non-thermal gas plasma; ER, endoplasmic reticulum; GRP78, glucose-related protein 78; p-PERK, phosphorylated protein kinase R (PKR)-like ER kinase; p-IRE1, phosphorylated inositol-requiring enzyme 1; p-eIF2 $\alpha$, phosphorylated eukaryotic initiation factor $2 \alpha$; XBP1, X-box binding protein 1; CHOP, CCAAT/enhancer-binding protein homologous protein.

before plasma exposure. We also monitored mitochondrial $\mathrm{Ca}^{2+}$ overload by confocal microscopy in cells stained with Rhod-2 AM. As expected, the confocal microscopy results (Fig. 4B) were consistent with the flow cytometry data. These findings suggest that plasma treatment triggers ER stress and mitochondrial $\mathrm{Ca}^{2+}$ accumulation, which in turn promotes apoptosis, in SNUC5 colon carcinoma cells. Because NAC pre-treatment could ameliorate these effects, it is likely that the ER stress is induced by excess ROS.

\section{Discussion}

As a widespread type of cancer, colorectal cancer represents a serious health threat throughout the world. Chemoresistance and side-effects of prolonged chemical treatments are substantial challenges for the treatment of colorectal cancer (5). Therefore, novel non-chemical strategies for treating colorectal cancer are urgently needed. NTGP has been characterized in various clinical applications as a promising tool for wound healing (27), plasma sterilization (28), blood coagulation (29), cell detachment (30), induction of apoptosis (31), and cancer therapy (32). Therefore, we investigated whether NTGP induces apoptosis in SNUC5 human colon carcinoma cells by generating ER stress.

For this study, we exposed cells to NTGP for 2 min using a non-thermal DBD plasma source. First, we investigated whether NTGP induces ROS. To this end, we stained plasmaexposed cells with DCFH-DA and examined them by flow cytometry and confocal microscopy (Fig. 1A and B). Data obtained by both methods indicated that plasma treatment significantly increased intracellular ROS generation. Furthermore, NTGP decreased cell viability compared to the controls (Fig. 2A) by inducing apoptosis (Fig. 2B). Pre-treatment with NAC attenuated these and all other consequences of plasma treatment, strongly indicating that cell death and other effects of plasma exposure are mediated by ROS.

Overwhelming ROS levels can trigger ER stress. Staining of cells with ER-Tracker ${ }^{\mathrm{TM}}$ Blue-White DPX dye confirmed 
A
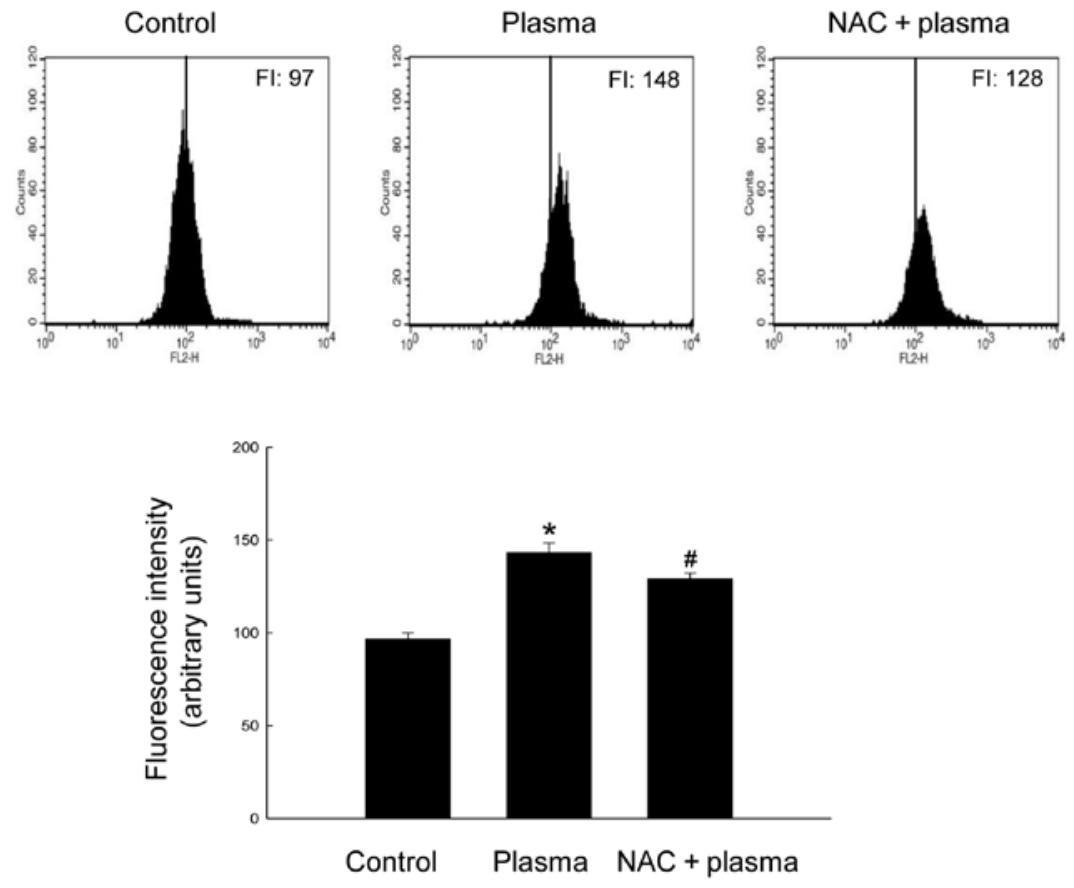

B
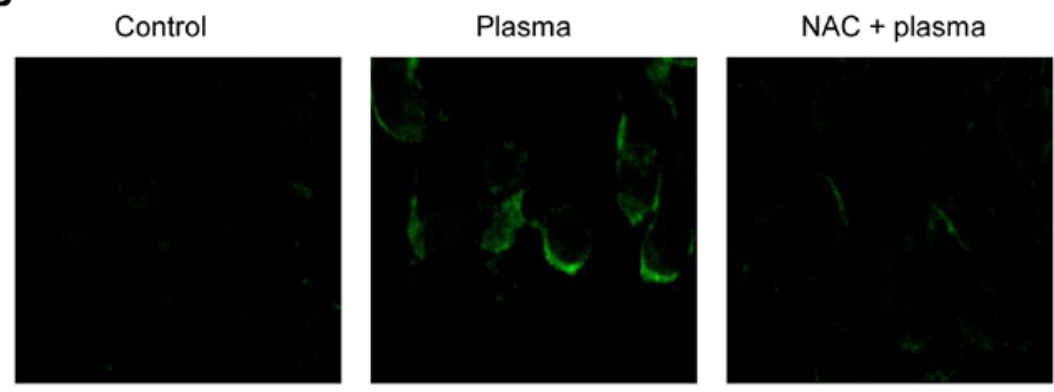

Figure 4. Influence of NTGP on mitochondrial $\mathrm{Ca}^{2+}$ overload. Control, plasma-treated, and NAC-pre-treated/plasma-treated cells were stained with Rhod-2 AM fluorescent dye, and mitochondrial $\mathrm{Ca}^{2+}$ overload was analyzed by (A) flow cytometry and (B) confocal microscopy. ${ }^{*}$ Significantly different from control cells $(\mathrm{p}<0.05)$; " significantly different from plasma-exposed cells $(\mathrm{p}<0.05)$. NTGP, non-thermal gas plasma; NAC, $N$-acetylcysteine.

that plasma treatment induced ER stress (Fig. 3A). A mean of combating the detrimental effects of ER-stressed cells is the UPR, whose basic purpose is to halt protein synthesis and accumulation of misfolded proteins until proper ER function can be restored. If the UPR cannot restore cellular homeostasis, it triggers apoptosis (16). Under normal conditions, GRP78 is bound to the luminal domains of PERK and IRE1, maintaining them in their inactive states. Upon ER stress, GRP78 dissociates from the receptors, allowing them to be phosphorylated (33). Once activated, the UPR halts protein synthesis and upregulates production of ER-resident chaperones that promote protein folding and help the cell recover from stress. Plasma treatment increased the levels of GRP78, p-PERK, and p-IRE1, and also activated PERK-mediated phosphorylation of p-eIF $2 \alpha$, which imposes a translational block on ER protein synthesis (33) (Fig. 3B). These results confirmed that plasma exposure activates key proteins involved in the UPR.

Persistent ER stress inhibits PERK and halts the UPR, ultimately resulting in apoptosis (34). Cleaved ATF6 translocates to the nucleus and initiates transcription of XBP1 and CHOP. XBP1 mRNA is unconventionally spliced by p-IRE1, enabling translation of XBP1 protein (34), which translocates to the nucleus and induces the expression of P58IPK, which inhibits p-PERK and initiates protein degradation (23). Plasma exposure increased the levels of both XBP1 and CHOP (Fig. 3B). CHOP downregulates the anti-apoptotic mitochondrial protein Bcl-2, increasing mitochondrial membrane permeability and releasing cytochrome $c$ into the cytoplasm to trigger apoptosis (35). $\mathrm{Ca}^{2+}$ accumulation in the mitochondria is a marker of the early and late stages of apoptosis (26). Because Bcl-2 expression is blocked under severe ER stress by activation of CHOP, $\mathrm{Ca}^{2+}$ can leak from the ER into the cytoplasm and mitochondria. Thus, mitochondrial $\mathrm{Ca}^{2+}$ overload is a hallmark of intensive ER stress (26). Consistent with this, plasma exposure strongly increased the mitochondrial $\mathrm{Ca}^{2+}$ level in SNUC5 cells (Fig. 4A and B).

These data confirm our hypothesis that NTGP induces apoptosis in SNUC5 human colon carcinoma cells via induction of ER stress. The attenuation of the UPR and related phenomena by NAC pre-treatment demonstrates that the effects of plasma exposure are mediated by generation of ROS. 


\section{Acknowledgements}

This study was supported by the R\&D Program of Plasma Advanced Technology for Agriculture and Food (Plasma Farming) through the National Fusion Research Institute (NFRI) of Korea funded by the Government.

\section{References}

1. Pietrzyk L, Torres A, Maciejewski R and Torres K: Obesity and obese-related chronic low-grade inflammation in promotion of colorectal cancer development. Asian Pac J Cancer Prev 16 4161-4168, 2015

2. Haggar FA and Boushey RP: Colorectal cancer epidemiology: Incidence, mortality, survival, and risk factors. Clin Colon Rectal Surg 22: 191-197, 2009.

3. Birmingham JM, Busik JV, Hansen-Smith FM and Fenton JI: Novel mechanism for obesity-induced colon cancer progression. Carcinogenesis 30: 690-697, 2009.

4. Morrison DS, Parr CL, Lam TH, Ueshima H, Kim HC, Jee SH, Murakami Y, Giles G, Fang X, Barzi F, et al: Behavioural and metabolic risk factors for mortality from colon and rectum cancer: Analysis of data from the Asia-Pacific Cohort Studies Collaboration. Asian Pac J Cancer Prev 14: 1083-1087, 2013.

5. Dy GK, Hobday TJ, Nelson G, Windschitl HE, O'Connell MJ, Alberts SR, Goldberg RM, Nikcevich DA and Sargent DJ: Long-term survivors of metastatic colorectal cancer treated with systemic chemotherapy alone: A north central cancer treatment group review of 3811 patients, n0144. Clin Colorectal Cancer 8 : 88-93, 2009.

6. Bussiahn R, Brandenburg R, Gerling T, Kindel E, Lange H, Lembke N, Weltmann KD, von Woedtke Th and Kocher T: The hairline plasma: An intermittent negative dc-corona discharge at atmospheric pressure for plasma medical applications. Appl Phys Lett 96: 143701, 2010.

7. Gadri RB, Roth JR, Montie TC, Kelly-Wintenberg K, Tsai PPY, Helfritch DJ, Feldman P, Sherman DM, Karakaya F and Chen Z; UTK Plasma Sterilization Team: Sterilization and plasma processing of room temperature surfaces with a one atmosphere uniform glow discharge plasma (OAUGDP). Surf Coat Tech 131: 528-541, 2000 .

8. Kim CH, Kwon S, Bahn JH, Lee K, Jun SI, Rack PD and Baek SJ: Effects of atmospheric nonthermal plasma on invasion of colorectal cancer cells. Appl Phys Lett 96: 243701, 2010.

9. Sensenig R, Kalghatgi S, Cerchar E, Fridman G, Shereshevsky A, Torabi B, Arjunan KP, Podolsky E, Fridman A, Friedman G, et al: Non-thermal plasma induces apoptosis in melanoma cells via production of intracellular reactive oxygen species. Ann Biomed Eng 39: 674-687, 2011.

10. Cheng X, Sherman J, Murphy W, Ratovitski E, Canady J and Keidar M: The effect of tuning cold plasma composition on glioblastoma cell viability. PLoS One 9: e98652, 2014.

11. Seo K, Ki SH and Shin SM: Methylglyoxal induces mitochondrial dysfunction and cell death in liver. Toxicol Res 30: 193-198, 2014

12. Park J, Bae EK, Lee C, Choi JH, Jung WJ, Ahn KS and Yoon SS: Establishment and characterization of bortezomib-resistant U266 cell line: Constitutive activation of NF- $\mathrm{KB}-$ mediated cell signals and/or alterations of ubiquitylation-related genes reduce bortezomib-induced apoptosis. BMB Rep 47: 274-279, 2014.

13. Elmore S: Apoptosis: A review of programmed cell death. Toxicol Pathol 35: 495-516, 2007.

14. Gaut JR and Hendershot LM: The modification and assembly of proteins in the endoplasmic reticulum. Curr Opin Cell Biol 5: 589-595, 1993.

15. Faitova J, Krekac D, Hrstka R and Vojtesek B: Endoplasmic reticulum stress and apoptosis. Cell Mol Biol Lett 11: 488-505, 2006.

16. Schröder M and Kaufman RJ: ER stress and the unfolded protein response. Mutat Res 569: 29-63, 2005.
17. Breckenridge DG, Germain $M$, Mathai JP, Nguyen $M$ and Shore GC: Regulation of apoptosis by endoplasmic reticulum pathways. Oncogene 22: 8608-8618, 2003.

18. Haertel B, Straßenburg S, Oehmigen K, Wende K, von Woedtke T and Lindequist U: Differential influence of components resulting from atmospheric-pressure plasma on integrin expression of human HaCaT keratinocytes. BioMed Res Int 2013: 761451, 2013.

19. Kim KC, Piao MJ, Madduma Hewage SR, Han X, Kang KA Jo JO, Mok YS, Shin JH, Park Y, Yoo SJ, et al: Non-thermal dielectric-barrier discharge plasma damages human keratinocytes by inducing oxidative stress. Int J Mol Med 37: 29-38, 2016.

20. Carmichael J, DeGraff WG, Gazdar AF, Minna JD and Mitchell JB: Evaluation of a tetrazolium-based semiautomated colorimetric assay: Assessment of chemosensitivity testing. Cancer Res 47: 936-942, 1987.

21. Fonteriz RI, de la Fuente S, Moreno A, Lobatón CD, Montero M and Alvarez $\mathrm{J}$ : Monitoring mitochondrial $[\mathrm{Ca}(2+)]$ dynamics with rhod-2, ratiometric pericam and aequorin. Cell Calcium 48: 61-69, 2010.

22. Szegezdi E, Logue SE, Gorman AM and Samali A: Mediators of endoplasmic reticulum stress-induced apoptosis. EMBO Rep 7: 880-885, 2006.

23. Yan W, Frank CL, Korth MJ, Sopher BL, Novoa I, Ron D and Katze MG: Control of PERK eIF2 $\alpha$ kinase activity by the endoplasmic reticulum stress-induced molecular chaperone P58IPK. Proc Natl Acad Sci USA 99: 15920-15925, 2002.

24. Lee AH, Iwakoshi NN and Glimcher LH: XBP-1 regulates a subset of endoplasmic reticulum resident chaperone genes in the unfolded protein response. Mol Cell Biol 23: 7448-7459, 2003.

25. Yamaguchi $\mathrm{H}$ and Wang HG: CHOP is involved in endoplasmic reticulum stress-induced apoptosis by enhancing DR5 expression in human carcinoma cells. J Biol Chem 279: 45495-45502, 2004.

26. Pinton P, Giorgi C, Siviero R, Zecchini E and Rizzuto R: Calcium and apoptosis: ER-mitochondria $\mathrm{Ca}^{2+}$ transfer in the control of apoptosis. Oncogene 27: 6407-6418, 2008.

27. Haertel B, von Woedtke T, Weltmann KD and Lindequist U: Non-thermal atmospheric-pressure plasma possible application in wound healing. Biomol Ther (Seoul) 22: 477-490, 2014

28. Moman RM, and Najmaldeen H: The bactericidal efficacy of cold atmospheric plasma technology on some bacterial strains. Egypt Acad J Biolog Sci 2: 43-47, 2010.

29. Kuo SP, Tarasenko O, Chang J, Popovic S, Chen CY, Fan HW, Scott A, Lahiani M, Alusta P, Drake JD, et al: Contribution of a portable air plasma torch to rapid blood coagulation as a method of preventing bleeding. New J Phys 11: 115016, 2009.

30. Hoentsch M, von Woedtke T, Weltmann KD and Nebe JB: Time-dependent effects of low-temperature atmospheric-pressure argon plasma on epithelial cell attachment, viability and tight junction formation in vitro. J Phys D: Appl Phys 45: 025206, 2012.

31. Tuhvatulin AI, Sysolyatina EV, Scheblyakov DV, Logunov DY, Vasiliev MM, Yurova MA, Danilova MA, Petrov OF, Naroditsky BS, Morfill GE, et al: Non-thermal plasma causes p53-dependent apoptosis in human colon carcinoma cells. Acta Naturae 4: 82-87, 2012.

32. Partecke LI, Evert K, Haugk J, Doering F, Normann L, Diedrich S, Weiss FU, Evert M, Huebner NO, Guenther C, et al: Tissue tolerable plasma (TTP) induces apoptosis in pancreatic cancer cells in vitro and in vivo. BMC Cancer 12: 473, 2012.

33. Lee AS: Glucose-regulated proteins in cancer: Molecular mechanisms and therapeutic potential. Nat Rev Cancer 14: 263-276, 2014.

34. van der Kallen CJ, van Greevenbroek MM, Stehouwer CD and Schalkwijk CG: Endoplasmic reticulum stress-induced apoptosis in the development of diabetes: Is there a role for adipose tissue and liver? Apoptosis 14: 1424-1434, 2009.

35. Tabas I and Ron D: Integrating the mechanisms of apoptosis induced by endoplasmic reticulum stress. Nat Cell Biol 13: 184-190, 2011 